\title{
From the editors
}

What a difference a year makes! A year ago, we were contemplating the world shutting down due to COVID and the pandemic. Facing such an uncertain future, we were not sure just how things would play out for the journal, even with 2020 being our 20 th anniversary! But the world has persevered and we can voice cautious optimism in the wake of the hope that vaccinations can bring, even though we clearly are not out of the woods yet globally and these are still potentially perilous times. Fortunately, we are able to say that the Journal of Greek Linguistics also persevered, and we can report the happy news of bringing out three solid issues more or less on time even under the severe restrictions that COVID has placed on us, on our authors, on our printers, and on our readers. We trust that all have weathered the storm successfully.

Despite everything, the journal's 2oth year was a good one, with several excellent papers in our pages, and the beginning of our third decade this year promises to be an even better one. Submissions are up-perhaps one upside to the pandemic, if more time at home has meant more time for writing on the part of our authors, though the positive turn the journal has taken towards open access may also have played a role — and for the first time ever we might be facing a backlog of publishable papers. This is a trend that we hope will continue, as we strive to keep on bringing a host of interesting and insightful papers to you, our readers, on a semi-annual basis.

The present issue has papers by somewhat younger scholars that show our usual mix of chronological stages of Greek-one entirely on Classical Greek (Goldstein), one entirely on Modern Greek (Tsiakmakis, Borràs-Comes, and Espinal), and one mostly on Classical Greek but with interesting glances at Medieval and Modern Greek as well (Hollenbaugh). Moreover, there is a mix of areas and methodologies within linguistics - syntax approached via statistical modeling (Goldstein), syntax approached via psycholinguistic experimentation (Tsiakmakis, Borràs-Comes, and Espinal), and diachronic semantics approached via formal semantics and pragmatics (Hollenbaugh). One novelty in this issue, something that is becoming increasingly common in journal publishing in general and especially in linguistics, is that for the first time we have articles (two, in this case as it happens) that have supplementary materials that are being published on the web, on the web service used by the publisher for this purpose, Figshare (https://brill.figshare.com/). These represent 
materials that are of relevance to the articles' content and are certain to be of interest to readers of the respective articles, but are not essential and so fit more into the category of useful reference material for those drawing on the findings in the articles.

We wish everyone connected with the journal-authors and readers especially - health and well-being in these continuing difficult but slowly brightening times.

Dag T.T. Haug, Brian D. Joseph and Anna Roussou 15 May 2021 